\title{
How do different extracorporeal circulation systems affect metoprolol bioavailability in coronary artery bypass surgery patients
}

\section{Kokki, Hannu}

2018-06

Kokki , H , Maaroos , M , Ellam , S, Halonen , J , Ojanpera , I , Ranta , M , Ranta , V-P , Tolonen, A , Lindberg , O , Viitala , M \& Hartikainen, J 2018 , ' How do different extracorporeal circulation systems affect metoprolol bioavailability in coronary artery bypass surgery patients ' , European Journal of Clinical Pharmacology , vol. 74 , no. 6 , pp. 785-792 . https://doi.org/10.1007/s00228-018-2437-1

http://hdl.handle.net/10138/302415

https://doi.org/10.1007/s00228-018-2437-1

publishedVersion

Downloaded from Helda, University of Helsinki institutional repository.

This is an electronic reprint of the original article.

This reprint may differ from the original in pagination and typographic detail.

Please cite the original version. 


\title{
How do different extracorporeal circulation systems affect metoprolol bioavailability in coronary artery bypass surgery patients
}

\author{
Hannu Kokki ${ }^{1,2}$ (D) Martin Maaroos ${ }^{3} \cdot$ Sten Ellam $^{2} \cdot$ Jari Halonen $^{1,3} \cdot$ Ilkka Ojanperä $^{4} \cdot$ Merja Ranta $^{4}$. \\ Veli-Pekka Ranta ${ }^{5}$. Aleksandra Tolonen ${ }^{3} \cdot$ Oscar Lindberg $^{6} \cdot$ Matias Viitala $^{6}$ • Juha Hartikainen ${ }^{1,3}$
}

Received: 11 November 2017 / Accepted: 28 February 2018 /Published online: 9 March 2018

(C) Springer-Verlag GmbH Germany, part of Springer Nature 2018

\begin{abstract}
Purpose Cardiac surgery and conventional extracorporeal circulation (CECC) impair the bioavailability of drugs administered by mouth. It is not known whether miniaturized ECC (MECC) or off-pump surgery (OPCAB) affect the bioavailability in similar manner. We evaluated the metoprolol bioavailability in patients undergoing CABG surgery with CECC, MECC, or having OPCAB.

Methods Thirty patients, ten in each group, aged 44-79 years, scheduled for CABG surgery were administered $50 \mathrm{mg}$ metoprolol by mouth on the preoperative day at $8-10$ a.m. and 8 p.m., 2 h before surgery, and thereafter daily at 8 a.m. and 8 p.m. Blood samples were collected up to $12 \mathrm{~h}$ after the morning dose on the preoperative day and on first and third postoperative days. Metoprolol concentration in plasma was analyzed using liquid chromatography-mass spectrometry.

Results The absorption of metoprolol was markedly reduced on the first postoperative day in all three groups, but recovered to the preoperative level on the third postoperative day. The geometric means ( $90 \%$ confidence interval) of $\mathrm{AUC}_{0-12}$ on the first and third postoperative days versus the preoperative day were 44 (26-74)\% and 109 (86-139)\% in the CECC-group, 28 (16-50)\% and $79(59-105) \%$ in the MECC-group, and $26(12-56) \%$ and $96(77-119) \%$ in the OPCAB-group, respectively. Two patients in the CECC-group and two in the MECC-group developed atrial fibrillation (AF). The bioavailability and the drug concentrations of metoprolol in patients developing AF did not differ from those who remained in sinus rhythm.

Conclusion The bioavailability of metoprolol by mouth was markedly reduced in the early phase after CABG with no difference between the CECC-, MECC-, and OPCAB-groups.
\end{abstract}

Keywords Metoprolol $\cdot$ Pharmacokinetics $\cdot$ Area under the curve $\cdot$ Atrial fibrillation $\cdot$ Postoperative $\cdot$ Coronary artery bypass grafting surgery

Hannu Kokki and Martin Maaroos contributed equally to this work.

The Principal Clinical Investigator is Prof. Juha Hartikainen.

Electronic supplementary material The online version of this article (https://doi.org/10.1007/s00228-018-2437-1) contains supplementary material, which is available to authorized users.

Hannu Kokki

hannu.kokki@uef.fi

1 School of Medicine, University of Eastern Finland, Kuopio, Finland

2 Department of Anaesthesia and Operative Services, Kuopio University Hospital, PO Box 100, 70029 Kuopio, KYS, Finland

3 Heart Centre, Kuopio University Hospital, Kuopio, Finland

4 Department of Forensic Medicine, University of Helsinki, Helsinki, Finland

5 School of Pharmacy, University of Eastern Finland, Kuopio, Finland

6 StatFinn \& EPID Research, Turku, Finland
Atrial fibrillation (AF) is the most common arrhythmia to occur after cardiac surgery. The incidence of AF has been reported to range between 20 and $45 \%$ after coronary artery bypass graft $(\mathrm{CABG})$ surgery and is even higher after valve and combined valve and bypass surgery [1-8]. Postoperative $\mathrm{AF}$ is associated with the risk of mortality and morbidity from stroke, heart failure, myocardial infarction, thromboembolism, bleeding from anticoagulation, hospital readmission, and increased costs [5, 9-11].

Beta-blockers reduce the incidence of AF after cardiac surgery [12-16]. Thus, the European Society of Cardiology (ESC) guidelines recommend routine preoperative and early postoperative beta-blocker therapy after cardiac surgery CABG [17]. Metoprolol is a commonly used beta-blocker. It is metabolized primarily by hepatic cytochrome P450 2D6 (CYP2D6) that is highly polymorphic [18]. The combined prevalence of extreme phenotypes, i.e., poor and ultrarapid metabolizers, is $10-20 \%$ among the Caucasians. A recent 
meta-analysis showed that the poor metabolizers have 13-fold area under the concentration-time curve (AUC) compared to ultrarapid metabolizers [18]. CYP2D6 is not inducible, but it is inhibited by several drugs.

However, in spite of beta-blockers, the risk of postoperative AF remains high, about 20\% [14]. Recently, it has been shown that intravenous beta-blocker is more efficient than beta-blocker by mouth in the prevention of postoperative $\mathrm{AF}$ [19]. This has been postulated to be due to reduced absorption of swallowed beta-blockers as a result of diminished visceral blood flow, delayed gastrointestinal motility, peri- and postoperative use of opioids, and inflammatory response caused by extracorporeal circulation (ECC) [20].

New techniques, such as miniaturized ECC (MECC), have been developed to reduce blood-air and blood-artificial material contact and, thus, inflammatory response compared to conventional ECC (CECC) [21-23]. In addition, an increasing number of $\mathrm{CABG}$ procedures are performed without any $\mathrm{ECC}$ (OPCAB) aiming to less surgical trauma and even less inflammatory reaction than with CECC or MECC [24, 25].

In this study, our hypothesis was that the surgical trauma to the body is less with MECC and OPCAB than that with CECC, and as the result, the gastrointestinal function is less disturbed and the absorption of metoprolol by mouth is preserved. To test this hypothesis, we planned a three-arm pharmacokinetic study where the primary outcome measure was the absorption of metoprolol by mouth on the preoperative, first and third postoperative days in patients scheduled for CABG with CECC, MECC, or OPCAB.

\section{Material and methods}

\section{Patients}

The study population consisted of 30 patients, aged between 44 and 79 years, who were scheduled for elective CABG surgery in the Kuopio University Hospital between November 2012 and March 2015.

The patients were given oral and written information of the trial protocol, and they all provided written consent. The study protocol was approved by the Research Ethics Committee of the Hospital District of Northern Savo, Kuopio, Finland (ref. 11// 2012), Finnish Medicines Agency was notified (ref. 63 // 2012), and it was registered in the European Clinical Trials Database (Eudra CT: 2012-001983-31) and was conducted in accordance with the Declaration of Helsinki. The study had institutional approval.

All patients aged between 18 and 80 years of age were included if they had no contraindication to metoprolol. Patients already using metoprolol were excluded, as were patients with a previous surgery of upper gastrointestinal tract, disease or any other condition that could interfere with the gastric absorption, moderate or severe hepatic or renal impairment, and patients having concomitant CYP2D6 inhibitors, such as diltiazem, fluoxetine, and paroxetin, in use. A total of 32 patients agreed were included, but two patients were withdrawn from the study: one due to postoperative hypotension and one due to logistic reasons. Thus, the final population consisted of 30 patients, all of who had a clinical indication for beta-blocker (Table S1-available in the "Electronic supplementary material").

\section{Metoprolol administration}

Patients arrived to the hospital on the day before surgery. A total of 23 patients were on beta-blockers (bisoprolol). They were not given the compound during the time they were on metoprolol. They were asked to fast for at least $2 \mathrm{~h}$ before the metoprolol administration. Each patient was given a 50-mg tablet of metoprolol tartrate (Metoprolin Ratiopharm; Merckle GmbH, Blaubeuren, Germany) with a glass of water $(150 \mathrm{~mL})$ at $8-10 \mathrm{a} . \mathrm{m}$. After this, they were asked to remain in an upright position for at least $30 \mathrm{~min}$, either sitting on a chair or walking around the ward. Fasting was continued for $4 \mathrm{~h}$ after the test drug administration, and at noon, the patients were served a light meal. The patients were provided with two additional doses of metoprolol $50 \mathrm{mg}$ before surgery: at 8 p.m. on the day before the surgery and at 6 a.m. on the day of the operation. Metoprolol administration was continued from the first postoperative morning: $50-\mathrm{mg}$ tablets were administered by mouth at 8 a.m. and at 8 p.m.

\section{Blood samples}

Blood samples $(3 \mathrm{~mL})$ were obtained with an indwelling catheter inserted in an antecubital vein at baseline (before drug administration) and at $0.5,1,1.5,2,2.5,3,4,6,8$, and $12 \mathrm{~h}$ after the morning dose on the preoperative day and on the first and the third postoperative days. The baseline sample was obtained before the $8 \mathrm{a} . \mathrm{m}$. administration of metoprolol, and the 12-h sample was obtained before the 8 p.m. metoprolol administration. Blood was collected into EDTA tubes, and plasma was obtained within $20 \mathrm{~min}$ of collection by centrifugation at $2100 \mathrm{~g}$ for $10 \mathrm{~min}$ at + $20^{\circ} \mathrm{C}$. The separated plasma was stored at $-76^{\circ} \mathrm{C}$ until analysis performed in two slots at the laboratory in the Department of Forensic Medicine, University of Helsinki, Helsinki, Finland. Arterial blood pressure and heart rate and rhythm were recorded after each blood sample.

\section{Outcome measures}

The primary outcome measure was AUC from time 0 to $12 \mathrm{~h}$ $\left(\mathrm{AUC}_{0-12}\right)$ on the first and third postoperative days compared to that on the preoperative day. The secondary outcomes were the peak concentration $\left(C_{\max }\right)$, time to peak concentration 
$\left(T_{\max }\right)$, and elimination half-life $\left(T_{1 / 2}\right)$. For clinical outcome measure, we used the incidence of postoperative $\mathrm{AF}$ and for safety parameter adverse events (AE).

\section{Anesthetic management and extracorporeal circulation}

Before surgery, the patients received premedication by mouth, diazepam 10-15 mg. Nitrides, statins, cortisone, and medication for chronic pulmonary disease were given from their drug list. Metoprolol was given according to the study protocol. A standardized anesthesia protocol was used for each patient (Appendix 1-Electronic supplementary material), and for ECC, customized perfusion sets were used (Appendix 2Electronic supplementary material).

\section{Plasma metoprolol concentrations}

The present method is a modification of the method published earlier [20] and involves minor updates in instrument analysis, while the extraction procedure was unchanged. The basic validation results remained the same, including the lower limit of quantification (LOQ) $1 \mu \mathrm{g} / \mathrm{L}$ (Appendix 3-Electronic supplementary material).

\section{Pharmacokinetic parameters}

Pharmacokinetic parameters $\left(\mathrm{AUC}_{0-12}, C_{\max }, T_{\max }, T_{1 / 2}\right)$ were calculated based on noncompartmental analysis using the Phoenix WinNonlin version 6.3 software (Certara, Princeton, NJ, USA). $\mathrm{AUC}_{0-12}$ was calculated using the linear trapezoidal rule. $T_{1 / 2}$ was determined only when there was a clear log-linear terminal phase.

\section{Statistics}

Sample size calculation was based on our earlier study in which the preoperative metoprolol $\mathrm{AUC}_{0-12}$ in $\mathrm{CECC}$ patients was $14.5 \mathrm{mg} \cdot \mathrm{min} / \mathrm{L}$ and that on the first postoperative day $7.8 \mathrm{mg} \cdot \mathrm{min} / \mathrm{L}$ (SD $5.4 \mathrm{mg} \cdot \mathrm{min} / \mathrm{L}$ ), respectively [20]. A sample size of 13 patients per group would provide a study power of $80 \%$ to detect a difference between groups at a significance level of 0.05 .

Within each group, paired analysis between the first postoperative day and the preoperative day and between the third postoperative day and the preoperative day were done for AUC $_{0-12}$ and $C_{\max }$ using two one-sided $t$ tests (paired-sample equivalence test). The hypothesis pair was tested with type I error rate of 5\% for each variable and study day separately, and the ratio of geometric means and its $90 \%$ confidence interval (CI) are reported. The analyses were performed with SAS ${ }^{\circledR}$ version 9.4 for Windows (SAS Institute Inc., Cary, NC, USA).
The between-group differences in the preoperative day and the first and third postoperative day $\mathrm{AUC}_{0-12}, C_{\max }$, and $T_{1 / 2}$ values (each day separately; $T_{1 / 2}$ only on the preoperative day) were analyzed with Kruskal-Wallis test and post hoc comparison between patients with $\mathrm{AF}$ and no-AF with MannWhitney test using the SigmaPlot version 13.0 software (Systat Software, Inc., San Jose, CA, USA). The Tukey test was used in all pair-wise comparisons.

Differences were regarded as statistically significant if the $P$ value was less than 0.05 . Descriptive statistics of the data are expressed as the number of cases and mean with standard deviation or median with minimum and maximum where appropriate.

\section{Results}

Due to logistical reasons, a total of 32 patients were enrolled and after two exclusions 30 patients were included in the final analysis, 10 patients in each group. The patients' characteristics are presented in Table 1. Data was not collected on the third postoperative day in three patients, one patient from each study group. Thus, we had 30 full data sets for the preoperative day and first postoperative day and 27 data sets for the third postoperative day. The third postoperative day data from one patient in the CECC-group were excluded from the analysis, since the metoprolol concentration in the baseline sample was $96 \%$ of the $C_{\max }$ observed later on that day indicating major carryover from the previous doses. In other subjects the median and mean carryover percentages were 8 and $11 \%$, respectively, meaning that the carryover did not affect the major findings of our study. The carryover was negligible in the baseline samples on the first postoperative day (the previous dose was taken 24-26 h earlier).

\section{Metoprolol bioavailability}

On the preoperative day, the pharmacokinetic parameters were similar in all three groups (Table 1). In contrary to our study hypothesis, there were no significant differences in $\mathrm{AUC}_{0-12}$ and $C_{\max }$ values between the study groups on the first or third postoperative days (Table 1, Figs. 1, 2, and 3). Significant interindividual variation was observed in all three study groups.

Within each group, the geometric mean of $\mathrm{AUC}_{0-12}$ on the first postoperative day was $26-44 \%$ of the preoperative value, and the upper limits of $90 \%$ CI (50-74\%) were significantly below $100 \%$, respectively (Table 2 ). On the third postoperative day, $\mathrm{AUC}_{0-12}$ had returned to $79-109 \%$ of the preoperative values, and $100 \%$ was always included in the $90 \% \mathrm{CI}$, respectively. A similar pattern was seen in $C_{\max }$, except that in the CECC-group, the whole $90 \%$ CI was slightly above $100 \%$ on the third postoperative day. On the first postoperative day, 
Table 1 Pharmacokinetic parameters for 50-mg metoprolol tablet after $\mathrm{CABG}$ in different treatment groups

\begin{tabular}{lllllll}
\hline Group & Study day & Number & $\mathrm{AUC}_{0-12}(\min \cdot \mu \mathrm{g} / \mathrm{L})$ & $C_{\max }(\mu \mathrm{g} / \mathrm{L})$ & $T_{\max }(\mathrm{min})$ & $T_{1 / 2}(\mathrm{~min})$ \\
\hline CECC & Preoperative & 10 & $18,500 \pm 15,800$ & $65 \pm 54$ & $94[58-180]$ & $226 \pm 54$ \\
& First postop. & 10 & $9820 \pm 11,400$ & $37 \pm 44$ & $151[27-732]$ & \\
& Third postop. & 8 & $26,300 \pm 26,300$ & $89 \pm 64$ & $94[60-712]$ & \\
MECC & Preoperative & 10 & $24,400 \pm 24,400$ & $98 \pm 91$ & $74[60-154]$ & $243 \pm 77$ \\
& First postop. & 10 & $7300 \pm 8060$ & $26 \pm 29$ & $602[85-745]$ & \\
& Third postop. & 9 & $17,800 \pm 19,200$ & $63 \pm 40$ & $89[30-255]$ & \\
OPCAB & Preoperative & 10 & $19,900 \pm 9860$ & $78 \pm 44$ & $80[30-154]$ & $189 \pm 35$ \\
& First postop. & 10 & $8600 \pm 8440$ & $27 \pm 27$ & $359[90-723]$ & \\
& Third postop. & 9 & $19,100 \pm 7910$ & $64 \pm 31$ & $180[60-483]$ & \\
\hline
\end{tabular}

Data are arithmetic means $\pm \mathrm{SD}$, except median [minimum-maximum] for $T_{\max }$

$C A B G$ coronary artery bypass surgery
$T_{\max }$ occurred later than in other study days in all study groups (Table 1). On the third postoperative day, there were two very late $T_{\max }$ values, one at $720 \mathrm{~min}$ in the CECC-group and one at $480 \mathrm{~min}$ in the OPCAB-group, respectively (Figs. 1 and 3).

Preoperatively, six patients in the CECC-group, six in the MECC-group, and nine in the OPCAB-group had $C_{\max }$ above the lower therapeutic reference value of $35 \mu \mathrm{g} / \mathrm{L}$ for metoprolol. On the first postoperative day four in the CECC-group, two in the MECC-group and three in the OPCAB-group had $C_{\max } \geq 35 \mu \mathrm{g} / \mathrm{L}$. On the third postoperative day, $C_{\max }$ values had resumed to the preoperative levels in all three groups, seven out of nine, six out of nine, and eight out of nine had $C_{\max } \geq 35 \mu \mathrm{g} / \mathrm{L}$ in the CECC-group, MECC-group, and OPCAB-group, respectively.

\section{Clinical outcome}

No patients in the OPCAB-group developed postoperative $\mathrm{AF}$, whereas two patients in the CECC-group and two in the MECC-group presented with postoperative AF. In a post hoc analysis, it appeared that the $\mathrm{AUC}_{0-12}$ and $C_{\max }$ and $T_{\max }$ values of the four patients with postoperative $\mathrm{AF}$ did not differ from those in 23 patients who recovered without $\mathrm{AF}$ (Table S2-available in the "Electronic supplementary material"). Preoperatively, all four patients with AF had $C_{\max } \geq 35 \mu \mathrm{g} / \mathrm{L}$ for metoprolol. On the first postoperative day, three out of four patients and on the third postoperative day all four patients with postoperative $\mathrm{AF}$ had $C_{\max } \geq$ $35 \mu \mathrm{g} / \mathrm{L}$, respectively (Table 2 ).

None of the patients died during the 30-day follow-up after cardiac surgery. Two patients, one in the CECC-group and one in the OPCAB-group, developed postoperatively respiratory insufficiency and were diagnosed to have pneumonia. They were readmitted to the intensive care unit, but thereafter, their recovery was uneventful. One patient in the OPCAB-group had protracted nausea on the first postoperative day, his AUC $_{0-12}$ were $18,850,3890$, and $16,230 \mathrm{~min} \cdot \mu \mathrm{g} / \mathrm{L}$ and $C_{\max }$ 74,7 , and $59 \mu \mathrm{g} / \mathrm{L}$ on preoperative, first, and third
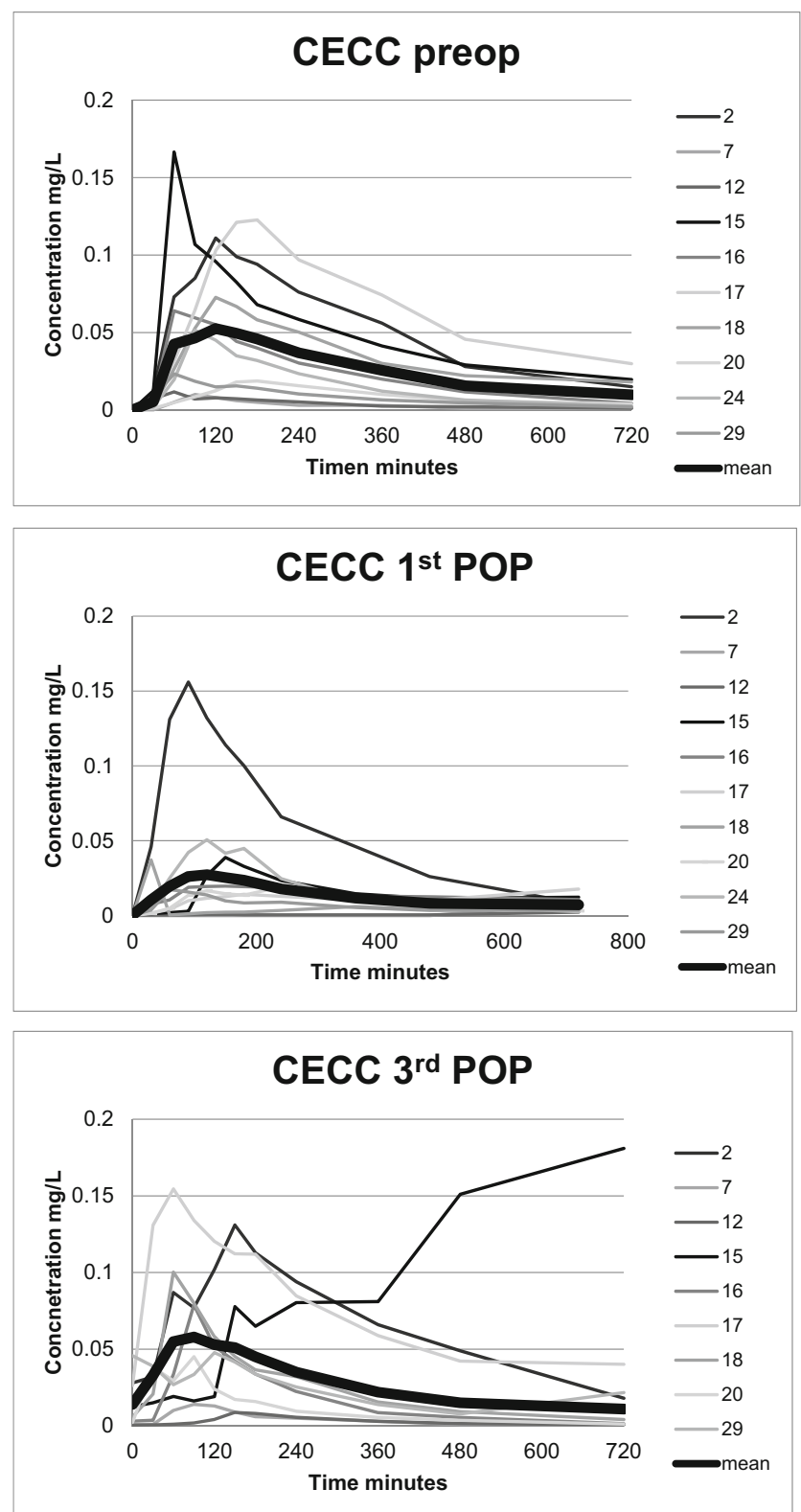

Fig. 1 Plasma concentrations of metoprolol in the CECC-group in the three study days 

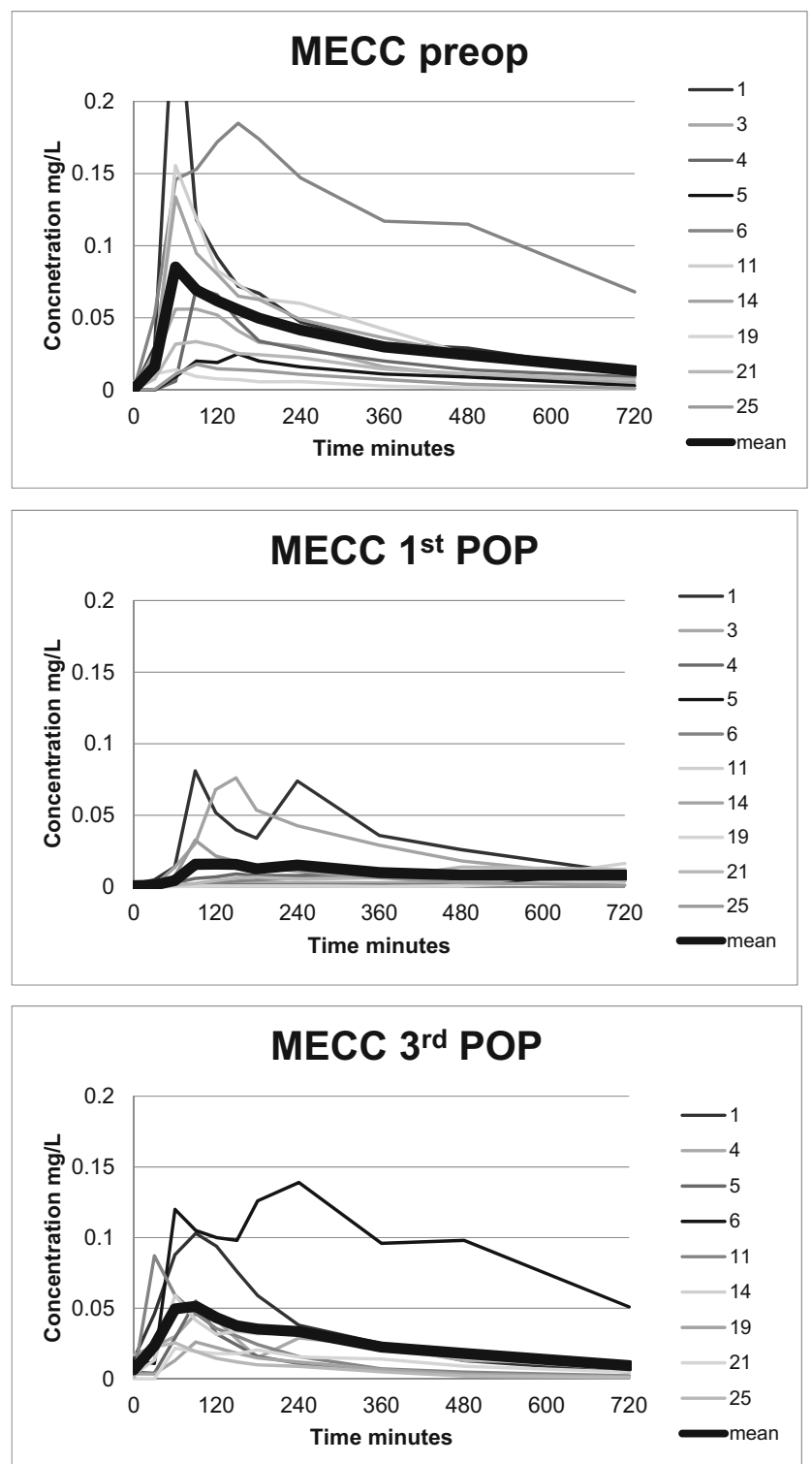

Fig. 2 Plasma concentrations of metoprolol in the MECC-group in the three study days

postoperative days, respectively. In the MECC-group, one patient had postoperative fever, one had subcutaneous emphysema, one had hypertension, and one had excessive drowsiness on the first postoperative day.

\section{Discussion}

The main findings of our study were, first, that the relative bioavailability of metoprolol reduced by $50-75 \%$ on the first postoperative day compared to that observed preoperatively; second, it resumed back to preoperative on the third postoperative day; and third, CECC, MECC, and OPCAP did not differ from each other with respect to metoprolol bioavailability. Our data is consistent to that reported earlier [20],
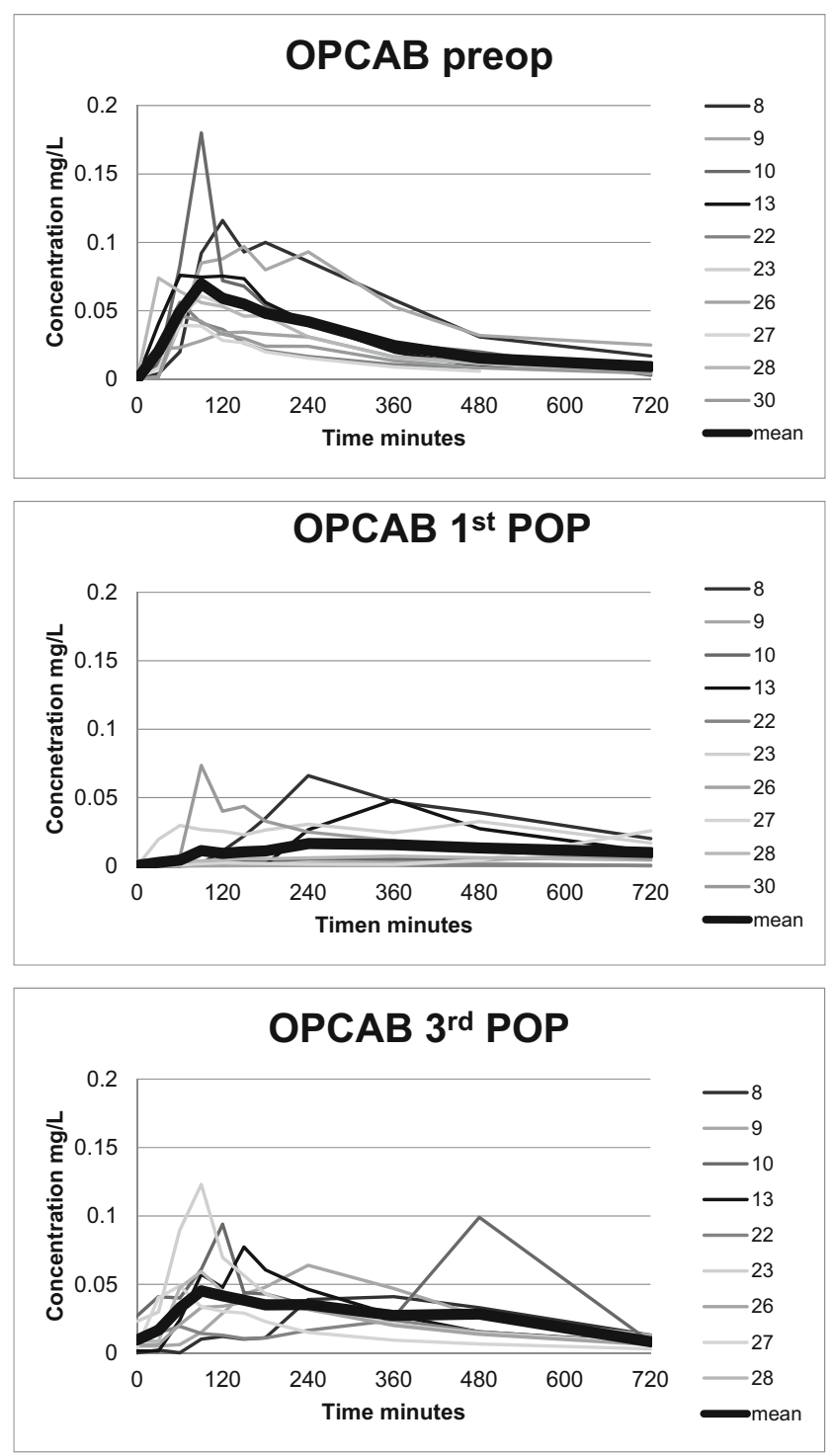

Fig. 3 Plasma concentrations of metoprolol in the OPCAB-group in the three study days

indicating that to achieve sufficient blood concentration of metoprolol in early phase after CABG surgery, it should be administered intravenously.

The pathophysiology of postoperative AF is not fully understood. On possible mechanism is systemic inflammatory response caused by ECC [26, 27]. It is assumed to render the heart vulnerable to arrhythmias. In addition, ECC has been suggested to impair drug absorption from the gastrointestinal tract resulting in reduced bioavailability of drugs, including beta-blockers. Indeed, Valtola et al. [20] reported that the bioavailability of orally administered metoprolol was markedly reduced during the early recovery phase after CABG. This is supported also by the study by Halonen et al. [19] in which the incidence of postoperative AF was significantly lower in patients treated with intravenous metoprolol as compared to metoprolol by mouth. 
Table 2 Pharmacokinetic parameters for 50-mg metoprolol tablet after CABG in different treatment groups

\begin{tabular}{|c|c|c|c|c|c|c|}
\hline \multirow[t]{2}{*}{ Group } & \multirow[t]{2}{*}{ Study day } & \multirow[t]{2}{*}{ Number } & \multicolumn{2}{|c|}{$\mathrm{AUC}_{0-12}$ geometric mean } & \multicolumn{2}{|c|}{$C_{\max }$ geometric mean } \\
\hline & & & Value $(\min \cdot \mu \mathrm{g} / \mathrm{L})$ & vs preop. day (\%) & Value $(\mu \mathrm{g} / \mathrm{L})$ & vs preop. day (\%) \\
\hline \multirow[t]{3}{*}{ CECC } & Preoperative & 10 & 11,700 & - & 44.3 & - \\
\hline & First postop. & 10 & 5130 & $44(26-74)$ & 21.5 & $49(30-78)$ \\
\hline & Third postop. & 8 & 14,200 & $109(86-139)$ & 59.9 & $127(103-157)$ \\
\hline \multirow[t]{3}{*}{ MECC } & Preoperative & 10 & 16,000 & - & 62.8 & \\
\hline & First postop. & 10 & 4470 & $28(16-50)$ & 15.8 & $25(13-47)$ \\
\hline & Third postop. & 9 & 12,700 & $79(59-105)$ & 52.0 & $82(55-122)$ \\
\hline \multirow[t]{3}{*}{ OPCAB } & Preoperative & 10 & 17,800 & - & 68.9 & \\
\hline & First postop. & 10 & 4610 & $26(12-56)$ & 14.7 & $21(9-50)$ \\
\hline & Third postop. & 9 & 17,800 & $96(77-119)$ & 57.1 & $79(56-112)$ \\
\hline
\end{tabular}

Data are geometric means of pharmacokinetic parameters and their postoperative versus preoperative comparison is the ratio of the means $(90 \%$ confidence interval) using $n$ according to the postoperative day

$C A B G$ coronary artery bypass surgery

Evolution of the cardiopulmonary bypass has emerged new techniques such as MECC to reduce the inflammatory response follow cardiac surgery [21-23]. Reducing the surface area of the circuit and removing the blood-air interface potentially offers several benefits compared to CECC including reduced hemodilution, postbypass coagulopathy, and inflammatory response $[28,29]$. Extracorporeal circulation can be completely avoided by using OPCAP technique. Indeed, there is some evidence that that OPCAB could minimize the risk of inflammatory response and gastrointestinal complications following cardiac surgery [30-32]. In the light is the above, it was of surprise that in our study the method of ECC was not related to the bioavailability of metoprolol; $\mathrm{AUC}_{0-12}, C_{\max }$, and $T_{\max }$ did not differ between patients undergoing $\mathrm{CABG}$ with CECC, MECC, or OPCAB methods. This suggests that systemic inflammation induced by ECC is not the only mechanism influencing metoprolol bioavailability.

Metoprolol tartrate is rapidly and almost completely absorbed from the GI tract indicating about 50\% first-pass metabolism [32]. It is poorly absorbed from the stomach, whereas it is well absorbed from the small intestine and the colon [19]. In healthy volunteers, following a single administration by mouth, metoprolol appears in the plasma within $10 \mathrm{~min}$ and $C_{\max }$ is reached within $90 \mathrm{~min}$ [32]. Accordingly, in our study at baseline, $C_{\max }$ were reached in 74-94 min, whereas on the first postoperative day, they prolonged to 151-602 min indicating slowing down of metoprolol absorption rate. Gastric emptying rate regulates the absorption rate of metoprolol from the small intestine. The rate, but not the extent of metoprolol absorption, is increased by the presence of food in the gastrointestinal tract [33, 34]. Opioids are known to inhibit down gastric emptying and intestinal motility [35]. Even on the third postoperative day, two subjects (of 27) had very late $T_{\max }$ values (480 and $720 \mathrm{~min}$ ), suggesting that the gastrointestinal function had not recovered completely in these subjects [20]. In our study, all patients were given opioids for postoperative pain. This is plausibly one of the mechanism responsible for the reduced metoprolol absorption after CECC, MECCV, but also OPCAB surgery.

The plasma metoprolol concentrations in our study were similar to those reported earlier [20,36]. In addition, we found a large interindividual variation in the metoprolol absorption; the lowest and highest $C_{\max }$ were 10 and $290 \mu \mathrm{g} / \mathrm{L}$ with 29 fold difference. The difference between lowest and highest $\mathrm{AUC}_{0-12}$ was even larger, 42-fold. In line with us, Valtola et al. [20] and Lundborg and Steen [36] reported a high, 15to 31-fold interindividual variation in the $C_{\max }$ after a single 50-mg dose of metoprolol by mouth. Both studies reported the lowest plasma metoprolol concentration to be far below the lower level of the therapeutic range $(35 \mu \mathrm{g} / \mathrm{L})$. The lowest $C_{\max }$ in their studies were 3 and $14 \mu \mathrm{g} / \mathrm{L}$, respectively, and in the present study, it was $10 \mu \mathrm{g} / \mathrm{L}$. The highest $C_{\max }$ were also similar, 140, 210, and $290 \mu \mathrm{g} / \mathrm{L}$, respectively $[20,36]$.

The high interindividual variation can be explained by the metabolism of metoprolol. Although metoprolol tartrate is almost completely absorbed from the gastrointestinal tract, it undergoes significant first-pass metabolism, and thus, the bioavailability is about $50 \%$ [32]. Metoprolol is metabolized predominantly by CYP2D6, and as there is high interindividual variation in the CYP2D6 activity, about $2-5 \%$ of the Caucasians being ultrarapid metabolizers and $5-10 \%$ slow metabolizers that results in significant variation in the interindividual exposure to metoprolol administered by mouth [18, 37]. In our study, the high values for the subject 6 in the MECC-group on the preoperative day $\left(C_{\max } 185 \mu \mathrm{g} / \mathrm{L}\right.$, $\mathrm{AUC}_{0-12} 84,900 \mathrm{~min} \cdot \mu \mathrm{g} / \mathrm{L}, T_{1 / 2} 7.0 \mathrm{~h}$ ) are similar to those of poor metabolizers in a recent meta-analysis [18]. Additionally, on the preoperative day, several subjects in our study had 
values similar to those of ultrarapid metabolizers in the same meta-analysis [18]. The lack of CYP2D6 genotyping is a limitation in our study. However, it does not weaken our conclusions on between-day comparison within each group, since the patients acted as their own controls.

In our study, four patients (13\%) developed AF. This is in line that with earlier reports on patients with CABG [18]. AF developed in one fifth of patients in the CECC-group and in the MECC-group whereas in none of the patients treated with OPCAB. However, our study was unpowered to evaluate the differences in the AF incidence between the groups. On the other hand, it was of surprise that the bioavailability of metoprolol assessed with $\mathrm{AUC}_{0-12}$ and $C_{\max }$ tended to be higher in the four AF patients compared to non-AF patients.

In conclusion, the bioavailability of metoprolol by was markedly reduced in the early phase after CABG with no difference between the CECC-, MECC-, and OPCAB-groups. One third of the patients with ECC developed postoperative $\mathrm{AF}$ but none in the OPCAB-group. As the pharmacokinetic parameters were similar in those with $\mathrm{AF}$ and no- $\mathrm{AF}$, in further studies, other parameters that may explain the difference should be evaluated.

Funding This study was funded by the governmental VTR-grant by the Hospital District of Northern Savo, Kuopio, Finland and Olvi Säätiö, Iisalmi, Finland.

\section{Compliance with ethical standards}

Conflict of interest The authors declare that they have no conflict of interest.

Ethical approval All procedures performed in studies involving human participants were in accordance with the ethical standards of the institutional and/or national research committee and with the 1964 Helsinki declaration and its later amendments or comparable ethical standards.

Informed consent Informed consent was obtained from all individual participants included in the study.

\section{References}

1. Svedjeholm R, Håkanson E (2000) Predictors of atrial fibrillation in patients undergoing surgery for ischemic heart disease. Scand Cardiovasc J 34:516-521

2. Zaman AG, Archbold A, Helft G, Paul EA, Gurzen NP, Mills PG (2000) Atrial fibrillation after coronary artery bypass surgery: a model for preoperative risk stratification. Circulation 101:1403-1408

3. Mahoney EM, Thompson TD, Veledar E, Williams J, Weintraub WC (2002) Cost-effectiveness of targeting patients undergoing cardiac surgery for therapy with intravenous amoidarone to prevent atrial fibrillation. J Am Coll Cardiol 40:737-745

4. Majahalme S, Kim MH, Bruckman D, Tarkka M, Eagle KA (2002) Atrial fibrillation after coronary surgery: comparison between different health care systems. Int J Cardiol 82:209-218
5. Lahtinen J, Biancari F, Salmela E, Mosorin M, Satta J, Rainio P, Rimpiläinen J, Lepojärvi M, Juvonen T (2004) Postoperative atrial fibrillation is a major cause of stroke after on-pump coronary artery bypass surgery. Ann Thorac Surg 77:1241-1244

6. Mathew JP, Fontes ML, Tudor IC, Ramsay J, Duke P, Mazer CD, Barash PG, Hsu PH, Mangano DT, Investigators of the Ischemia Research and Education Foundation, Multicenter Study of Perioperative Ischemia Research Group (2004) A multicenter risk index for atrial fibrillation after cardiac surgery. JAMA 291:1720-1729

7. Ahlsson AJ, Bodin L, Lundblad OH, Englund AG (2007) Postoperative atrial fibrillation is not correlated to C-reactive protein. Ann Thorac Surg 83:1332-1337

8. Arsenault KA, Yusuf AM, Crystal E et al (2013) Interventions for preventing post-operative atrial fibrillation in patients undergoing heart surgery. Cochrane Database Syst Rev 1:Cd003611

9. Almassi GH, Schowalter T, Nicolosi AC, Aggarwal A, Moritz TE, Henderson WG, Tarazi R, Shroyer AL, Sethi GK, Grover FL, Hammermeister KE (1997) Atrial fibrillation after cardiac surgery: a major morbid event? Ann Surg 226:501-513

10. Hakala T, Pitkänen O, Hippeläinen M (2002) Feasibility of predicting the risk of atrial fibrillation after coronary artery bypass surgery with logistic regression model. Scand J Surg 91:339-344

11. Steinberg BA, Zhao Y, He X et al (2014) Management of postoperative atrial fibrillation and subsequent outcomes in contemporary patients undergoing cardiac surgery: insights from the Society of Thoracic Surgeons CAPS-Care Atrial Fibrillation Registry. Clin Cardiol 37:7-13

12. Andrews TC, Reimond SC, Berlin JA, Antman EM (1991) Prevention of supraventricular arrhythmias after coronary artery bypass surgery. A meta-analysis of randomized trials. Circulation 84:236-244

13. Kowey PR, Taylor JE, Rials SL, Marinchak RA (1992) Metaanalysis of the effectiveness of prophylactic drug therapy in preventing supraventriculat arrhythmias early after coronary artery bypass grafting. Am J Cardiol 69:963-965

14. Crystal E, Connolly SJ, Sleik K, Ginger TJ, Yusuf S (2002) Intervention on prevention of postoperative atrial fibrillation in patients undergoing heart surgery. A meta-analysis. Circulation 106:75-80

15. Wurdeman RL, Mooss AN, Mohiuddin SM, Lenz TL (2002) Amiodarone vs sotalol as prophylaxis against atrial fibrillation/ flutter after heart surgery. A meta-analysis. Chest 121:1203-1210

16. Zimmer J, Pezzullo J, Choucair W, Southard J, Kokkinos P, Karasik P, Greenberg MD, Singh SN (2003) Meta-analysis of antiarrhythmic therapy in the prevention of postoperative atrial fibrillation and the effect on hospital length of stay, costs, cerebrovascular accidents, and mortality in patients undergoing cardiac surgery. Am J Cardiol 91:1137-1140

17. Kirchhof P, Benussi S, Kotecha D, Ahlsson A, Atar D, Casadei B, Castella M, Diener HC, Heidbuchel H, Hendriks J, Hindricks G, Manolis AS, Oldgren J, Popescu BA, Schotten U, van Putte B, Vardas P, Agewall S, Camm J, Baron Esquivias G, Budts W, Carerj S, Casselman F, Coca A, de Caterina R, Deftereos S, Dobrev D, Ferro JM, Filippatos G, Fitzsimons D, Gorenek B, Guenoun M, Hohnloser SH, Kolh P, Lip GYH, Manolis A, McMurray J, Ponikowski P, Rosenhek R, Ruschitzka F, Savelieva I, Sharma S, Suwalski P, Tamargo JL, Taylor CJ, van Gelder IC, Voors AA, Windecker S, Zamorano JL, Zeppenfeld K (2016) 2016 ESC guidelines for the management of atrial fibrillation developed in collaboration with EACTS. Eur Heart J 37:2893-2962

18. Blake CM, Kharasch ED, Schwab M, Nagele P (2013) A metaanalysis of CYP2D6 metabolizer phenotype and metoprolol pharmacokinetics. Clin Pharmacol Ther 94:394-399

19. Halonen J, Hakala T, Auvinen T et al (2006) Intravenous administration of metoprolol is more effective than peroral administration in the prevention of atrial fibrillation after cardiac surgery. Circulation 114(suppl):I1-I4 
20. Valtola A, Kokki H, Gergov M, Ojanperä I, Ranta VP, Hakala T (2007) Does coronary artery bypass surgery affect metoprolol bioavailability. Eur J Clin Pharmacol 63:471-478

21. Remadi JP, Rakotoarivello Z, Marticho P, Trojette F, Benamar A, Poulain H, Tribouilloy C (2004) Aortic valve replacement with the minimal extracorporeal circulation (Jostra MECC system) versus standard cardiopulmonary bypass: a randomized prospective trial. J Thorac Cardiovasc Surg 128:436-441

22. Kiaii B, Fox S, Swinamer SA, Rayman R, Higgins J, Cleland A, Fernandes P, MacDonald J, Dobkowski WB, Stitt LW, Novick RJ, Singh B, Bureau Y, Summers K (2012) The early inflammatory response in a mini-cardiopulmonary bypass system: a prospective randomized study. Innovations (Phila) 7:23-32

23. Nguyen BA, Fiorentino F, Reeves BC et al (2016) Mini bypass and proinflammatory leukocyte activation: a randomized controlled trial. Ann Thorac Surg 101:1454-1463

24. Koivisto SP, Wistbacka JO, Rimpiläinen R, Nissinen J, Loponen P, Teittinen K, Biancari F (2010) Miniaturized versus conventional cardiopulmonary bypass in high-risk patients undergoing coronary artery bypass surgery. Perfusion 25:65-70

25. Harling L, Punjabi PP, Athanasiou T (2011) Miniaturized extracorporeal circulation vs. off-pump coronary artery bypass grafting: what the evidence shows? Perfusion 26(suppl 1):40-47

26. Hall RI, Smith MS, Rocker G (1997) The systemic inflammatory response to cardiopulmonary bypass: pathophysiological, therapeutic, and pharmacological considerations. Anesth Analg 85:766-782

27. Wan S, LeClerc JL, Vincent JL (1997) Inflammatory response to cardiopulmonary bypass: mechanisms involved and possible therapeutic strategies. Chest 112:676-692

28. Zangrillo A, Garozzo FA, Biondi-Zoccai G, Pappalardo F, Monaco F, Crivellari M, Bignami E, Nuzzi M, Landoni G (2010) Miniaturized cardiopulmonary bypass improves short-term outcome in cardiac surgery: a meta-analysis of randomized controlled studies. J Thorac Cardiovasc Surg 139:1162-1169

29. Benedetto U, Angeloni E, Refice S, Capuano F, Goracci M, Roscitano A, Sinatra R (2009) Is minimized extracorporeal circulation effective to reduce the need for red blood cell transfusion in coronary artery bypass grafting? Meta-analysis of randomized controlled trials. J Thorac Cardiovasc Surg 138:1450-1453

30. Croome KP, Kiaii B, Fox S et al (2009) Comparison of gastrointestinal complications in on-pump versus off-pump coronary artery bypass grafting. Can J Surg 52:125-128

31. Emmiler M, Yaveri A, Koçoğullari CU, Ela Y, Șahin DA, Sivaci RG, Cekirdekci A (2009) Gastrointestinal ischemia related mortality in patients undergoing off- or on-pump coronary artery bypass grafting. Heart Surg Forum 12:E79-E84

32. Regårdh C-G, Johnsson G (1980) Clinical pharmacokinetics of metoprolol. Clin Pharmacokinet 5:557-569

33. Godbillon J, Evard D, Vidon N et al (1985) Investigation of drug absorption from the gastrointestinal tract of man. III. Metoprolol in the colon. Br J Clin Pharmacol 19(Suppl 2):113-118

34. Jobin G, Cortot A, Godbillon J, al e (1985) Investigation of drug absorption from the gastrointestinal tract of man. I. Metoprolol in the stomach, duodenum and jejunum. Br J Clin Pharmacol 19(Suppl 2):97-105

35. Heyland DK, Tougas G, King D, Cook DJ (1996) Impaired gastric emptying in mechanically ventilated, critically ill patients. Intens Care Med 22:1339-1344

36. Lundborg P, Steen B (1976) Plasma levels and effect on heart rate and blood pressure of metoprolol after acute oral administration in 12 geriatric patients. Acta Med Scand 200:397-402

37. Fux R, Mörike K, Pröhmer AM et al (2005) Impact of CYP2D6 genotype on adverse effects during treatment with metoprolol: a prospective clinical study. Clin Pharmacol Ther 78:378-387 